\title{
Genetic markers for inherited thrombophilia are associated with fetal growth retardation in the population of Central Russia
}

\author{
Evgeny Reshetnikov ${ }^{1}$, Oksana Zarudskaya $^{1}$, Alexey Polonikov ${ }^{2}$, Olga Bushueva ${ }^{2}$, \\ Valentina Orlova ${ }^{3}$, Evgeny Krikun ${ }^{4}$, Volodymyr Dvornyk ${ }^{5,6}$ and Mikhail Churnosov ${ }^{1}$ \\ ${ }^{1}$ Department of Medical Biological Disciplines, ${ }^{3}$ Department of Obstetrics and Gynecology, ${ }^{4}$ Medical College, Belgorod State University, \\ Belgorod, ${ }^{2}$ Department of Biology, Medical Genetics and Ecology, Kursk State Medical University, Kursk, Russia and ${ }^{5}$ School of \\ Biological Sciences, University of Hong Kong, Pokfulam, Hong Kong, China and ${ }^{6}$ Department of Life Sciences, College of Science and \\ General Studies, Alfaisal University, Saudi Arabia
}

\begin{abstract}
Aim: The aim of this study was to examine the role of hereditary thrombophilia in the development of fetal growth retardation (FGR) in the population of Central Russia.

Methods: The case-control study sample included 497 women in the third trimester of pregnancy recruited during 2009-2013. The participants were enrolled into two groups: patients with FGR $(n=250)$ and controls without FGR $(n=247)$. The participants were genotyped for four genetic markers of hereditary thrombophilia: factor V Leiden ( $G>A F V$, rs6025), prothrombin ( $G>A$ FII, rs1799963), factor VII (G > A FVII, rs6046), and fibrinogen ( $G>A F I$, rs1800790).

Results: The genetic factors for an increased risk of FGR were allele $G$ of rs6046 (odds ratio $[O R]=2.34$ ) and genotype $G G$ of rs6046 (OR = 2.64), whereas genotype $G A$ of rs6046 had the protective value $(\mathrm{OR}=0.42)$. A combination of alleles $G$ of rs1799963, $A$ of rs6046, and $G$ of rs1800790 $(\mathrm{OR}=0.31)$ reduces the risk of FGR.
\end{abstract}

Conclusion: Polymorphism rs6046 of the FVII gene is associated with the development of FGR.

Key words: factor VII coagulant, fetal growth retardation, pregnancy, single nucleotide polymorphism.

\section{Introduction}

Thrombophilia is the pathological condition of the body characterized by an increased risk of intravascular thrombosis due to inherited or acquired disorders of hemostasis. ${ }^{1,2}$ Women with acquired or inherited thrombophilia are at increased risk for thrombotic and gestational complications. ${ }^{3-10}$ At least $50 \%$ of thrombotic complications of pregnancy are associated with thrombophilia. ${ }^{6,11}$ Thrombophilia is the most important risk factor for several obstetric complications, for example, fetal loss syndrome $(39.1 \%)$, severe preeclampsia $(18.2 \%)$, chorionic detachment $(11.5 \%)$, thrombosis during pregnancy and the post-partum period, and placental abruption $(13.63 \%) .{ }^{12}$ The most significant markers for the development of gestational complications of congenital thrombophilia are mutation Leiden 1691G > A FV, prothrombin 20210G > A FII, plasminogen activator inhibitor $4 G>5 G$ PAI-1, 677S > $T$ MTHFR, deficiency of protein $\mathrm{S}$, protein $\mathrm{C}$, antithrombin III, and others. ${ }^{9,10,12}$ Over $52 \%$ of women with obstetric complications have thrombophilic gene defects. ${ }^{7}$

Factor V Leiden thrombophilia is caused by a substitution of $\mathrm{G}$ by A at position 1691 of the gene and, respectively, replacement of arginine by glutamine at

Received: November 232016

Accepted: February 122017.

Correspondence: Correspondence: Evgeny Reshetnikov, Department of Medical Biological Disciplines, Belgorod State University, 85

Pobedy Q1 St, Belgorod 308015, Russia. Email: reshetnikov@bsu.edu.ru 
position 506 of the protein. ${ }^{13,14}$ This results in resistance of the factor $\mathrm{V}$ Leiden variant to inactivation by the activated protein $C$ and thus promotes clotting. ${ }^{14,15}$ The polymorphism inheritance follows the autosomal dominant principle. About $4-7 \%$ of European Caucasians are heterozygous for this mutation. ${ }^{16}$

The 20210G > A FII variant of prothrombin is located in the $3^{\prime}$-untranslated region of the gene. Although this substitution does not result in an amino acid change, it was associated with the up to 1.5-2 times elevated level of the normal prothrombin. ${ }^{17}$ The elevated level of prothrombin results in the higher level of thrombin that activates clotting through the positive feedback mechanism. Such an activation of the clotting mechanism confers an increased risk of thrombosis. ${ }^{17}$ Inheritance of the polymorphism follows the autosomal dominant principle. The frequency of heterozygotes in Caucasians is about $2-5 \%$. ${ }^{118,19}$

The $-455 G>A F I$ polymorphism is located in the promoter of the fibrinogen $\beta$-chain. It has been associated with the increased risk of thrombosis. ${ }^{20}$ The prevalence of this polymorphism in European populations is $5-10 \%{ }^{1}$

Mutation 10976G > A FVII results in a replacement of Arg by Gln in position 353 of the respective protein. This mutation was associated with the low concentration of the FVII protein in blood plasma. ${ }^{21}$ Heterozygotes 10976G > A FVII have 25\% lower concentration of the protein, homozygotes $10976 A A-50 \%$ lower as compared to the most common genotype 10976GG. In addition, homozygotes 10976GG are at higher risk for cardiovascular health problems and complications at pregnancy. ${ }^{21,22}$ The frequency in the European population is $10-20 \%{ }^{23,24}$

The available data about the role of the genetic markers for inherited thrombophilia in the fetal growth retardation are inconsistent. Several studies have reported a significant association of the 1691G > A FV with FGR in Caucasian females from: Canada (odds ratio $[\mathrm{OR}]=2.7 ; 95 \%$ confidence interval $[\mathrm{CI}], 1.3-5.5),{ }^{5}$ the USA (OR $=1.23 ; 95 \% \mathrm{CI}, 1.04-1.44),{ }^{25}$ and France $(\mathrm{OR}=2.58 ; \quad 95 \% \mathrm{CI}, \quad 0.83-8.04) .{ }^{26}$ The significant association of the $20210 \mathrm{G}>\mathrm{A}$ FII polymorphism with FGR was determined in Caucasian women from Canada $(\mathrm{OR}=2.5 ; 95 \% \mathrm{CI}, 1.3-5.0)^{5}$ and France $(\mathrm{OR}=$ 2.03; 95\%CI, 0.51-8.01). ${ }^{26}$ The contradictory data were reported by Franchi et al., ${ }^{4}$ who did not find significant associations of the 1691G > A FV, 20210G > A FII, and 677C/T MTHFR polymorphisms with FGR. We have not found any data about the association of the $-455 G$ $>$ A FI and 10976G > A FVII polymorphisms with FGR.

\section{Methods}

\section{Study population}

In total, 497 unrelated pregnant women in the third trimester of pregnancy were recruited for the study during 2009-2013. All participants signed an informed consent before entering the study. The clinical and laboratory examination of the participants was conducted in the perinatal center of the Saint Joasaph Belgorod Regional Clinical Hospital. The following inclusion criteria were used to check eligibility of the participants: singleton pregnancy and Russian ethnicity. Patients having congenital malformations of internal genitals, uterine fibroids, anomalies of placental location, isosensitization of $\mathrm{Rh}$ factor or $\mathrm{ABO}$, or genetic diseases Q5 were excluded from the study.

Two hundred and fifty participants were diagnosed with the syndrome of intrauterine growth retardation of varying severity. The diagnosis of the syndrome was based on clinical data, ultrasound fetometry (TOSHIBA XARIO SSA-660A) and parameters of growth and weight after the birth. Based on the differences between the fetometric data and nomograms, three degrees of FGR were classified: first degree corresponded to the reduction of the estimated gestational ages from the standard ones by 2 weeks; second degree - by 3-4 weeks; and third degree - by more than 4 weeks. ${ }^{27}$

The controls were 247 women without the syndrome of intrauterine growth retardation.

\section{DNA isolation and genotyping assay}

Each participant donated $6 \mathrm{~mL}$ of blood drawn from a cubital vein. Genomic DNA was isolated according to Miller et al. ${ }^{28}$ The participants were genotyped for four candidate genetic markers for hereditary thrombophilia: Leiden mutation of coagulation factor $\mathrm{V}(G>A F V$, rs6025), prothrombin ( $G>A$ FII, rs1799963), factor VII ( $G>A$ FVII, rs6046), and fibrinogen (G/A FI, rs1800790).

The polymorphisms were genotyped using the TaqMan real-time PCR assays with the standard primers and probes (Syntol, Russia). ${ }^{29,30}$ The data were processed using BioRad CFX Manager 3.1 (Bio-Rad Laboratories, Inc.).

\section{Statistical analysis}

The obtained genotypes were checked for their correspondence to the Hardy-Weinberg distribution (HWE) using the $\chi^{2}$-test. Association of the polymorphisms with FGR was estimated by analyzing $2 \times 2$ contingency tables with the $\chi^{2}$-test and Yates' correction for continuity. The risk was estimated using 
OR with $95 \% \mathrm{CI}$. Association of the polymorphisms with FGR was analyzed using logistic regression with adjustment for cofactors (somatic and gynecological pathologies). The analyses were performed using STATISTICA 6.0 (StatSoft).

Possible allele combinations of the studied polymorphisms and their significance for FGR were analyzed using the Markov chain Monte Carlo and Bayes nonparametric statistics as implemented in APSampler (http://sources.redhat.com/cygwin/). ${ }^{31}$ Bonferroni correction was applied to adjust for multiple comparisons.

\section{Results}

The summary characteristics of the case and control groups are given in Table 1.

First-degree FGR was diagnosed in 133 patients $(53.20 \%)$, second-degree in 96 patients $(38.40 \%)$, and third-degree in 21 patients $(8.40 \%)$.

The FGR patients had a 1.8-fold higher rate of spontaneous abortion predominantly in the first trimester of pregnancy than the controls.

All genotypes but one showed no deviation from the HWE. The only case of the deviation was observed in the case group at the G/A FV rs6025 locus $\left(\chi^{2}=6.58 ; P\right.$
$<0.05)$. This can be explained by the presence of a single homozygote $A A F V$ rs6025. After this genotype was removed, no deviation was observed $\left(\chi^{2}=0.09 ; P>\right.$ 0.05).

FGR patients had higher frequency of allele G FVII rs6046 (88.72\%) and genotype GG FVII rs6046 (77.87\%), and lower frequency of genotype GA FVII rs6046 $(21.70 \%)$ as compared to the controls $(77.07 \%, 57.07 \%$, and $40.00 \%$, respectively; Table 2 ).

The frequency of a combination of alleles G FII rs1799963, A FVII rs6046, and G FI rs1800790 was approximately half $(19.8 \%)$ that in the case group as compared to the controls $(44.5 \%)(\mathrm{OR}=0.31 ; 95 \% \mathrm{CI}$, 0.20-0.48; PFischer's $<0.0001$, BBonferroni $<0.0001)$.

The results of the logistic regression analysis showed that polymorphism G > A FVII rs6046 was significantly associated with a risk for FGR both individually and after adjustment for the cofactors, which were present in the patients and absent in the controls (i.e., miscarriage, essential hypertension; Table 3).

\section{Discussion}

The present study shows the association of genetic markers of hereditary thrombophilia G > A FVII rs6046 with the development of FGR in the population of

Table 1 Physical characteristics and various medical pathologies in the study participants

\begin{tabular}{|c|c|c|c|}
\hline & FRG patients, $n(\%)$ & Controls, $n(\%)$ & $P$ \\
\hline$N$ & 250 & 247 & - \\
\hline Age, years (min-max) & $26.78 \pm 4.81(16.0-45.0)$ & $26.20 \pm 5.01(19.0-41.0)$ & $>0.05$ \\
\hline $\mathrm{BMI}, \mathrm{kg} / \mathrm{m}^{2}$ & $23.37 \pm 4.31$ & $23.90 \pm 3.96$ & $>0.05$ \\
\hline \multicolumn{4}{|l|}{ Somatic pathologies } \\
\hline Essential hypertension & $50(20.00)$ & $29(11.74)$ & 0.02 \\
\hline Chronic pyelonephritis & $63(25.20)$ & 55 (22.27) & 0.51 \\
\hline Obesity & $23(9.20)$ & $22(8.91)$ & 1.00 \\
\hline Varicose veins & $13(5.20)$ & $10(4.05)$ & 0.69 \\
\hline Venous thromboembolism at pregnancy & $4(1.60)$ & $1(0.41)$ & 0.38 \\
\hline Chronic gastroduodenitis & $26(10.40)$ & $22(8.89)$ & 0.68 \\
\hline History of cerebrovascular disease & $2(0.80)$ & 0 & 0.50 \\
\hline \multicolumn{4}{|l|}{ Gynecological pathologies } \\
\hline History of medical abortion & $80(32.00)$ & $65(26.32)$ & 0.20 \\
\hline History of infertility & $5(2.00)$ & $8(3.24)$ & 0.56 \\
\hline History of miscarriage (total) & $46(18.40)$ & $25(10.12)$ & 0.01 \\
\hline Miscarriage in first trimester & $36(14.40)$ & $20(8.10)$ & 0.04 \\
\hline Pregnancy loss in first trimester & $12(4.80)$ & $12(4.86)$ & 1.00 \\
\hline Ectopic pregnancy & $10(4.00)$ & $15(6.07)$ & 0.39 \\
\hline History of disorders of the menstrual cycle & $20(8.00)$ & $14(5.67)$ & 0.39 \\
\hline History of pelvic inflammatory disease & $58(23.20)$ & $59(23.89)$ & 0.94 \\
\hline Intrauterine infection during pregnancy & $83(33.20)$ & $80(32.39)$ & 0.68 \\
\hline Pre-eclampsia & $55(22.00)$ & $68(27.53)$ & 0.19 \\
\hline Antenatal intrauterine fetal death & $4(1.60)$ & 0 & 0.14 \\
\hline
\end{tabular}


Table 2 Frequencies of the studied SNP and respective genotypes in case and control samples

\begin{tabular}{|c|c|c|c|c|c|c|}
\hline Polymorphism & Studied groups & Alleles, genotypes & Frequency, $\%$ & OR (95\%CI) & $\chi^{2}$ & $P$ \\
\hline \multirow[t]{8}{*}{$G>A$ FII rs1799963 } & Case & G & 98.40 & $0.44(0.09-1.83)$ & 0.87 & 0.35 \\
\hline & Control & G & 99.29 & & & \\
\hline & Case & GG & 96.80 & $0.44(0.09-1.83)$ & 0.88 & 0.35 \\
\hline & Control & GG & 98.58 & & & \\
\hline & Case & GA & 3.20 & $2.29(0.55-11.04)$ & 0.88 & 0.35 \\
\hline & Control & GA & 1.42 & & & \\
\hline & Case & $\mathrm{AA}$ & 0 & - & - & - \\
\hline & Control & $\mathrm{AA}$ & 0 & - & - & - \\
\hline \multirow[t]{8}{*}{$G>A$ FI rs1800790 } & Case & $\mathrm{G}$ & 79.20 & $1.18(0.87-1.61)$ & 1.04 & 0.31 \\
\hline & Control & G & 76.32 & - & - & - \\
\hline & Case & GG & 64.40 & $1.27(0.87-1.86)$ & 1.47 & 0.23 \\
\hline & Control & GG & 58.70 & - & - & - \\
\hline & Case & GA & 29.60 & $0.77(0.52-1.15)$ & 1.55 & 0.21 \\
\hline & Control & GA & 35.22 & - & - & - \\
\hline & Case & AA & 6.00 & $0.99(0.46-2.19)$ & 0.001 & 1.00 \\
\hline & Control & $\mathrm{AA}$ & 6.07 & - & & - \\
\hline \multirow[t]{8}{*}{$G>A F V r s 6025$} & Case & $\mathrm{G}$ & 97.77 & $0.59(0.19-1.74)$ & 0.63 & 0.43 \\
\hline & Control & G & 98.67 & & & \\
\hline & Case & GG & 95.95 & $0.65(0.21-1.97)$ & 0.34 & 0.56 \\
\hline & Control & GG & 97.35 & - & - & - \\
\hline & Case & GA & 3.64 & $1.32(0.44-4.46)$ & 0.12 & 0.73 \\
\hline & Control & GA & 2.65 & - & - & - \\
\hline & Case & $\mathrm{AA}$ & 0.40 & - & - & - \\
\hline & Control & $\mathrm{AA}$ & 0 & - & - & - \\
\hline \multirow{8}{*}{$G>A$ FVII rs6046 } & Case & $\mathrm{G}$ & 88.72 & $2.34(1.60-3.44)$ & 20.53 & 0.0005 \\
\hline & Control. & G & 77.07 & - & - & - \\
\hline & Case & GG & 77.87 & $2.64(1.71-4.09)$ & 20.88 & 0.0005 \\
\hline & Control & GG & 57.07 & - & - & - \\
\hline & Case & GA & 21.70 & $0.42(0.27-0.64)$ & 16.52 & 0.0006 \\
\hline & Control & GA & 40.00 & - & - & - \\
\hline & Case & $\mathrm{AA}$ & 0.43 & $0.21(0.01-2.03)$ & 1.13 & 0.29 \\
\hline & Control & $\mathrm{AA}$ & 2.93 & - & - & - \\
\hline
\end{tabular}

Table 3 Results of the univariate regression analysis ( $P$-values) of association of the $G>A$ FVII $r s 6046$ polymorphism with FGR

\begin{tabular}{lcc}
\hline Parameters & $\begin{array}{c}\text { Genotype } \\
\text { rs6046 }\end{array}$ & $\begin{array}{c}\text { Genotype adjusted } \\
\text { for cofactors }\end{array}$ \\
\hline $\begin{array}{c}\text { History of } \\
\text { miscarriage } \\
\text { (total) }\end{array}$ & 0.0003 & 0.04 \\
$\begin{array}{c}\text { Miscarriage in } \\
\text { first trimester }\end{array}$ & 0.004 & 0.04 \\
$\begin{array}{c}\text { Essential } \\
\text { hypertension }\end{array}$ & 0.003 & 0.04 \\
\hline
\end{tabular}

Central Russia. Genetic factors of an increased risk for FGR are allele G FVII rs6046 and genotype GG FVII rs6046, whereas allele $A$ FVII $r s 6046$ has a protective value. The combination of alleles G FII, A FVII, and G $F I$ reduces the risk of FGR $(\mathrm{OR}=0.31 ; 95 \% \mathrm{CI}, 0.20-0.48)$.

The association of the rs6046 polymorphism of the FVII gene with FGR remained significant after adjustment for cofactors (miscarriage and essential hypertension). However, the significance level was lower $(P=0.04$ vs $P=0.003-0.004$ without the adjustment). This may be due to the opposite effect of this polymorphism and the cofactors: Allele A was protective for FGR (OR $=0.43$ for allele A [95\%CI, 0.29-0.63] and 0.42 for genotype GA [95\%CI, 0.27-0.64]), while essential hypertension and miscarriage were 1.7-1.8-fold more common in the FGR patients than in the controls, which was implicated in a higher risk for FGR. ${ }^{32,33}$

The observed association of the G > A FVII rs6046 polymorphism with the development of FGR is consistent with the available data on the physiological role of this factor in the hemostatic system. According to modern concepts, coagulation factor VII (proconvertin) is one of the key factors in the coagulation cascade and participates in the external way of the activation of blood coagulation. ${ }^{22,34}$ The complex consisting of tissue factor, the active form of the 
Genes and fetal growth retardation

Table 4 Literature data about the association of the hereditary thrombophilia and FGR in various Caucasian populations

\begin{tabular}{|c|c|c|}
\hline Country & Results/conclusions & Reference \\
\hline Canada & Association of Leiden 1691G/A FV with FGR (OR = 2.7; 95\%CI, 1.3-5.5) & Howley et al. ${ }^{5}$ \\
\hline USA & Association of Leiden 1691G/A FV with FGR (OR = 1.2; 95\%CI, 1.04-1.44) & Facco et al. ${ }^{25}$ \\
\hline France & Association of Leiden 1691G/A FV with FGR (OR = 2.6; 95\%CI, 0.83-8.04) & Verspyck et al. ${ }^{26}$ \\
\hline Canada & Association of prothrombin 20210G/A FII with FGR (OR = 2.5; 95\%CI, 1.3-5.0) & Howley et al. ${ }^{5}$ \\
\hline France & Association of prothrombin 20210G/A FII with FGR (OR = 2.0; 95\%CI, 0.51-8.01) & Verspyck et al. ${ }^{26}$ \\
\hline Italy & No association of Leiden 1691G/A FV and prothrombin 20210G/A FII with FGR & Franchi et al. ${ }^{4}$ \\
\hline
\end{tabular}

FGR, fetal growth retardation.

coagulation factor VIIa, and calcium ions promotes formation of the active forms of factor $\mathrm{X}(\mathrm{Xa})$, which is a common way of initiating the coagulation cascade. In addition, the complex is able to activate factor IX (IXa) of the intrinsic pathway of blood coagulation that further strengthens the process of blood coagulation. ${ }^{22,34}$ The Factor VII gene is located on the long arm of chromosome 13 (13q34). The GA heterozygotes and $A A$ homozygotes of FVII rs6046 have, respectively, approximately $25 \%$ and $50 \%$ lower blood concentration of Factor VII as compared with the wild-type GG heterozygotes. ${ }^{21,35}$ The elevated levels of this factor can result in a hypercoagulable state and thrombotic complications, ${ }^{21,22,33}$ causing the development of placental insufficiency with the formation of FGR.

We have not found any significant associations of markers G > A FI rs1800790, G > A FII rs1799963, or G $>A$ FV rs6025 with a risk for FGR. This is in concordance with some previous studies on American and European Caucasians, ${ }^{1,4}$ whereas it contradicts other studies ${ }^{5,25,26}$ (Table 4).

The inconsistency in the results may be related to the respective differences in the ethnic and genetic backgrounds of the studied populations. Population genetic stratification was shown to have a significant effect on the prevalence and expression of quantitative traits in various populations. ${ }^{36}$

The results of the study show that the polymorphism $G>A$ FVII rs6046 alone, as well as in combination with other markers of hereditary thrombophilia, $G>A F I$ rs1800790 and $G>A$ FII rs1799963, is associated with the development of FGR. These results extend the existing ideas about the role of hereditary thrombophilia in the pathogenesis of placental insufficiency syndrome and fetal growth retardation.

\section{Disclosure}

No author has any potential conflict of interest.

\section{References}

1. Silver RM, Zhao Y, Spong CY et al. Prothrombin gene G20210A mutation and obstetric complication. Eunice Kennedy Shriver National Institute of Child health and Human Development Maternal-Fetal Medicine Units (NICHD MFMU) network. Obstet Gynecol 2010; 115: 14-20.

2. Martinelli I, Passamonti SM, Bucciarelli P. Thrombophilic states. Handb Clin Neurol 2014; 120: 1061-1071.

3. Anteby EY, Musalam B, Milwidsky A et al. Fetal inherited thrombophilias influence the severity of preeclampsia, IUGR and placental abruption. Eur J Obstet Gynecol Reprod Biol 2004; 113: 31-35.

4. Franchi F, Cetin I, Todros Tet al. Intrauterine growth restriction and genetic predisposition to thrombophilia. Haematologica 2004; 89: 444-449.

5. Howley HE, Walker M, Rodger MA. A systematic review of the association between factor $\mathrm{V}$ Leiden or prothrombin gene variant and intrauterine growth restriction. Am J Obstet Gynecol 2005; 192: 694-708.

6. Stella CL, Sibai BM. Thrombophilia and adverse maternalperinatal outcome. Clin Obstet Gynecol 2006; 49: 850-860.

7. Kovacheva K, Simeonova M, Ivanov P. Inherited thrombophilia and pregnancy with fetal loss. Akush Ginekol (Sofia) 2007; 46: 8-14.

8. Ivanov $\mathrm{P}, \mathrm{Komsa-Penkova} \mathrm{R}$, Konova $\mathrm{E}$ et al. Inherited thrombophilic factors in women with unexplained intrauterine fetal deaths. Akush Ginekol (Sofia) 2009; 48: 3-7.

9. Larciprete G, Rossi F, Deaibess $T$ et al. Double inherited thrombophilias and adverse pregnancy outcomes: Fashion or science? J Obstet Gynaecol Res 2010; 36: 996-1002.

10. Said JM, Higgins JR, Moses EK, Walker SP, Monagle PT, Brennecke SP. Inherited thrombophilias and adverse pregnancy outcomes: A case-control study in an Australian population. Acta Obstet Gynecol Scand 2012; 91: 250-255.

11. Carbone JF, Rampersad R. Prenatal screening for thrombophilias: Indications and controversies. Clin Lab Med 2010; 30: 747-760.

12. Korsar A, Kasapoglu B, Kalyoncu S, Turan H, Balcik OS, Gümüs EI. Treatment of adverse perinatal outcome in inherited thrombophilias: A clinical study. Blood Coagul Fibrinolysis 2011; 22: $14-18$.

13. Bertina RM, Koeleman BP, Koster T et al. Mutation in blood coagulation factor $\mathrm{V}$ associated with resistance to activated protein C. Nature 1994; 369: 64-67.

14. Lindqvist PG, Svensson PJ, Marsál K et al. Activated protein C resistance (FV:Q506) and pregnancy. Thromb Haemost 1999; 81: 532-537. 
15. Varga EA, Kujovich JL. Management of inherited thrombophilia: Guide for genetics professionals. Clin Genet 2012; 81: 7-17.

16. Kujovich JL, Factor V. Leiden thrombophilia. Genet Med 2011; 13: 1-16.

17. Poort SR, Rosendaal FR, Reitsma PH, Bertina RM. A common genetic variation in the $3^{\prime}$-untranslated region of the prothrombin gene is associated with elevated plasma prothrombin levels and an increase in venous thrombosis. Blood 1996; 88: 3698-3703.

18. Rodger MA, Betancourt MT, Clark P et al. The association of factor $\mathrm{V}$ Leiden and prothrombin gene mutation and placenta-mediated pregnancy complications: A systematic review and meta-analysis of prospective cohort studies. PLoS Med 2010; 7: e1000292.

19. Finan RR, Tamim H, Ameen G, Sharida HE, Rashid M, Almawi WY. Prevalence of factor V G1691A (factor V Leiden) and prothrombin G20210A gene mutations in a recurrent miscarriage population. Am J Hematol 2002; 71: 300-305.

20. Endler G, Mannhalter C. Polymorphisms in coagulation factor genes and their impact on arterial and venous thrombosis. Clin Chim Acta 2003; 330: 31-55.

21. Seremak-Mrozikiewicz A, Drews K, Kurzawińska G, Barlik M, Mrozikiewicz PM. The connection between Arg353Gln polymorphism of coagulation factor VII and recurrent miscarriages. Ginekol Pol 2009; 80: 8-13.

22. Shanker J, Perumal G, Maitra A et al. Genotype-phenotype relationship of F7 R353Q polymorphism and plasma factor VII coagulant activity in Asian Indian families predisposed to coronary artery disease. J Genet 2009; 88: 291-297.

23. Mrozikiewicz PM, Cascorbi I, Ziemer S et al. Reduced procedural risk for coronary catheter interventions in carriers of the coagulation factor VII-Gln353 gene. J Am Coll Cardiol 2000; 36: 1520-1525.

24. Mo X, Hao Y, Yang X, Chen S, Lu X, Gu D. Association between polymorphisms in the coagulation factor VII gene and coronary heart disease risk in different ethnicities: A meta-analysis. BMC Med Genet 2011; 12: 107-115.
25. Facco F, You W, Grobman W. Genetic thrombophilias and intrauterine growth restriction: A meta-analysis. Obstet Gynecol 2009; 113: 1206-1216.

26. Verspyck E, Borg JY, Le Cam-Duchez V et al. Thrombophilia and fetal growth restriction. Eur J Obstet Gynecol Reprod Biol 2004; 113: 36-40.

27. Hadlock FP, Deter RL, Harrist RB. Sonographic detection of abnormal fetal growth patterns. Clin Obstet Gynecol 1984; 27: 342-351.

28. Miller SA, Dykes DD, Polesky HF. A simple salting out procedure for extracting DNA from human nucleated cells. Nucleic Acids Res 1988; 16: 1215.

29. McGuigan FE, Ralston SH. Single nucleotide polymorphism detection: Allelic discrimination using TaqMan. Psychiatr Genet 2002; 12: 133-136.

30. Shen GQ, Abdullah KG, Wang QK. The TaqMan method for SNP genotyping. Methods Mol Biol 2009; 578: 293-306.

31. Favorov AV, Andreewski TV, Sudomoina MA, Favorova OO, Parmigiani G, Ochs MF. A Markov chain Monte Carlo technique for identification of combinations of allelic variants underlying complex diseases in humans. Genetics 2005; 171: 2113-2121.

32. Weintraub AY, Sergienko R, Harlev A et al. An initial miscarriage is associated with adverse pregnancy outcomes in the following pregnancy. Am J Obstet Gynecol 2011; 205: 286.

33. Moyambe JN, Bernard P, Khang'Mate F et al. Risk factors for intra-uterine growth retardation in Lubumbashi. Pan Afr Med J 2013; 14: 4.

34. Lopaciuk S, Windyga J, Watala CW et al. Polymorphisms in the factor VII gene and ischemic stroke in young adults. Blood Coagul Fibrinolysis 2010; 21: 442-447.

35. Nour M, Slama FB, Maaroufi RM, Hammami M, Mahjoub T. Factor VII polymorphisms associated with plasma factor VII coagulant activity levels in healthy Tunisians. East Mediterr Health J 2005; 11: 102-108.

36. Dvornyk V, Liu XH, Shen H et al. Differentiation of Caucasians and Chinese at bone mass candidate genes: Implication for ethnic difference of bone mass. Ann Hum Genet 2003; 67: 216-227. 